Journal of Thermal Engineering, Vol. 4, No. 1, pp. 1702-1712, January, 2018

Yildiz Technical University Press, Istanbul, Turkey

\title{
THEORETICAL INVESTIGATION OF A SOLAR AIR HEATER ROUGHENED BY RIBS AND GROOVES
}

\author{
C. Yıldırım ${ }^{1, *}$, N. F. Tümen Özdil²
}

\begin{abstract}
In this study, thermal and thermohydraulic efficiencies of a solar air collector having a roughened absorber with rib-grooved artificial roughness elements have been investigated and compared with the flat plate solar air collectors. The system has been theoretically investigated for different geometrical roughness parameters by help of energy balance equations between the elements of collector. Geometrical roughness parameters such as ratio of the relative roughness height (RRH), relative roughness pitch (RRP), and groove positions to pitch (GP/PR) are examined for Reynolds number range from 3000 to 21,000.
\end{abstract}

\section{Keywords: Solar Energy; Artificial Roughness of Solar Air Heater; Rib and Groove Type Roughness}

\section{INTRODUCTION}

Solar energy is one of the favored sustainable energy production ways among renewable energy sources. This energy is favored for low cost and without any limitation. Air and water solar heaters are frequently used for low temperature requirements. Solar air heaters have some advantages over solar water heaters. Because of its simplicity, solar air heaters are cheap and used in many countries of the world. Besides there is no leakage, corrosion, freezing or boiling risk. However, poor thermal and physical properties of air are disadvantages. Main application of solar air heaters are space heating, greenhouse heating, drying and desalination. There are various operational, design and meteorological parameters affecting solar air efficiency. For example, air mass flow rate, inlet air temperature, depth of the channel, collector length, collector width, glazing type and number, optical properties of glazing, emissivity of absorber plate, wind speed, solar intensity and ambient temperature etc. directly affect the thermal efficiency, thermo-hydraulic efficiency and exergy efficiency.

Oztop et al. [1] reviewed recent works on solar air heater based on energy and exergy analysis.

Ong [2] proposed a mathematical model and investigated four different types of solar air heater. He [3] also compared theoretical results with experimental ones. In his study, he obtained satisfactory qualitative and quantitative agreement between theoretical and experimental works.

Yıldırım and Solmuş [4] investigated the thermal and thermohydraulic efficiency of double pass solar air heater theoretically. Their investigation was based on transient mathematical model. Their study explored the dynamics of double pass solar air heater during whole day.

Yadav and Bhagoria [5] investigated fluid flow characteristics of fully developed turbulent flow in a rectangular duct having repeated transverse square sectioned rib roughness on the absorber plate using ANSYS FLUENT. They examined twelve different configurations of square sectioned rib. They concluded that the best thermo-hydraulic performance parameter were the square sectioned transverse rib roughened duct with $\mathrm{P} / \mathrm{e}=10.71$ and $\mathrm{e} / \mathrm{D}=0.042$.

Acir and Ata [6] studied heat transfer, friction factor and thermal performance factor characteristics for a new solar air heater. They performed experimental tests using various turbulators. They obtained the empirical equations from experimental results. They found thermal performance factor as $\sim 2.9$.

Rajaseenivasan et al. [7] carried out performance enrichment a single pass solar air heater using circular and V-shape inserts. They tested conventional and modified solar air heaters using different Reynolds numbers. They found that the system efficiency increases with Reynolds number and number of turbulators in absorber plate. Moreover, they concluded that first law, thermohydraulic and second law efficiency reached their highest values for type-f at Reynolds number of 11615.

This paper was recommended for publication in revised form by Regional Editor Derya Burcu Özkan

${ }^{1}$ Department of Mechanical Engineering, Adana Science and Technology University, Adana, TURKEY

2 Department of Mechanical Engineering, Adana Science and Technology University, Adana, TURKEY

*E-mail address: ycihan@adanabtu.edu.tr

Manuscript Received 16 June 2016, Accepted 27 September 2016 
Yang et al. [8] optimized the design of a solar air heater with offset strip fins using numerical modeling. They conducted a lot of experiments to check the detailed thermal performance of the heater in the light of time constant, thermal efficiency, incident angle modifier and the synthetical resistance coefficient. They refereed that developed model would be useful for developing energy efficient and cost effective solar air heaters.

Saxena et al. [9] performed some applications for solar energy for cooking, heating and cooling, and power generation. They designed a solar air heater (SAH) to produce a good exhaust temperature for long hours especially in the case of poor ambient conditions or during off sunshine hours. They conducted the experiments for natural and forced convection to evaluate the performance of two similar designed solar air heaters. They found that better thermal efficiency was observed for forced convection.

Alam et al. [10] investigated the effect of circularity of perforation holes on heat transfer of solar air heater. They examined five different hole shapes with Reynolds number of flow was varied between 2000 and 20,000. They found perforation holes, which were an optimum non-circular shape, yielded maximum value of Nusselt number.

Yadav et al. [11] evaluated exergetic performance of solar air heater having arc shape. They calculated exergetic efficiency of solar air heater analytically using developed correlations. They compared the results with a smooth flat-plate solar air heater. They investigated also effect of the the Reynolds number on exergetic efficiency. They found that, the smooth conventional flat-plate solar air heater was convenient for the Reynolds number greater than 20,000. The exergy efficiency could be worse for the higher Reynolds number.

Alam et al. [12] analyzed the effect of geometrical parameters of the V-shaped perforated blocks on heat transfer. Those geometrical parameters were accepted as relative blockage height, relative pitch ratio and open area ratio. They found the maximum increment in Nusselt and friction factor as 6.76 and 28.84 times to that of smooth duct, respectively.

Nowzari et al. [13] examined a solar air heater with different configurations, experimentally. A model was developed for the tested solar air heater using IBM's Statistical Package for the Social Sciences software. It was found that double-pass solar collector with a quarter-perforated cover with 3-cm hole-to-hole spacing had the highest thermal efficiency.

Jin et al. [14] presented a numerical investigation of heat transfer for a solar air heater duct having multi V-shaped ribs. They performed three-dimensional simulations using ANSYS FLUENT. They determined the maximum value of the thermal performance parameter as 1.93 .

Verma and Varshney [15] investigated the parameters on thermo-hydraulic performance of wire screen matrix packed solar air heater. The effective efficiency was evaluated by C++ computer programming using solving the governing equations numerically. According to the effective efficiency value, an optimum duct depth, duct length and width, which caused the best thermo-hydraulic performance, were determined in this study.

Deo et al. [16] conducted an experimental study for performance analysis of solar air heater. The effect of the Reynolds number, the rib pitch-to-height, the rib height-to-hydraulic diameter and angle of attack was investigated in this study. Two peaks for Nusselt number corresponding to the P/e value were determined. They found thermohydraulic performance parameter as 3.34 and 2.45 times, respectively.

Singh et al. [17] compared thermo-hydraulic performance rib roughness under investigation, 'V-down ribs with gap' and similar reported rib roughness geometries. They tested five rib roughened plates. They found the Nusselt number and friction factor as highest for relative roughness pitch of 8. They concluded that thermo-hydraulic performance varied from 1.27 to 1.93.

Yıldırım and Solmuş [18] investigated four different types' solar air heaters with different configurations. They compare the energy and exergy efficiency of the systems.

Yıldırım and Solmuş [19] studied the parametric behavior of a solar air heater having artificially protruded absorber plate. They examine the energy and exergy efficiency of the artificially roughened solar air heater.

Jaurker et al. [20] conducted an experimental study with rib \& groove type roughness element and they calculate correlations for Nusselt number and friction coefficient.

In this study, effect of the artificially roughened absorber plate with rib \& groove type roughness element is investigated on the thermal and thermohydraulic efficiencies.

\section{MATERIAL AND METHOD Mathematical Models}

Theoretical analysis of this study is based on thermal network of the solar air heater. Energy balance equations are constructed for each part of the collector and solved simultaneously. Roughness geometries are shown in Figure 1. The energy balance equations for 
the various parts of solar air heaters have been formulated under the following simplifying assumptions: (i) The system is steady state. (ii) There is no temperature gradient across the thickness of the system parts, so temperature of upper and lower sides are the same. (iii) There is no air leakage, so mass balance is kept. (iv). The air temperature varies linearly throughout section length. The mean air temperature is then equal to the arithmetic mean of inlet and outlet temperature of section.
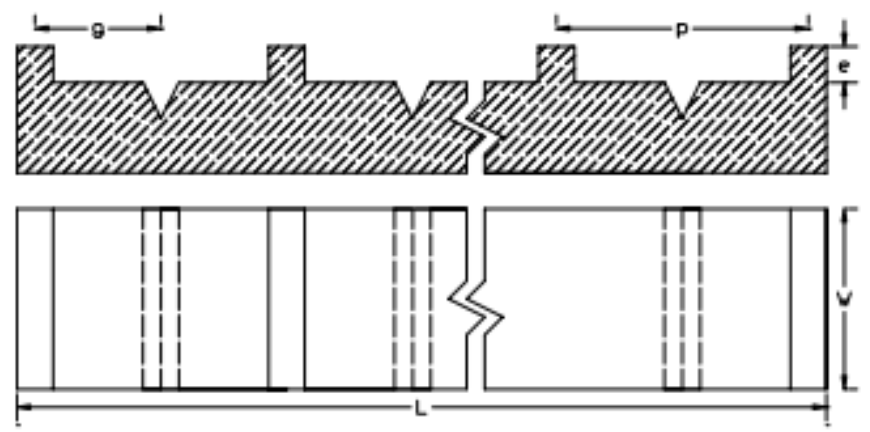

Figure 1. Schematic representation of solar air heater absorber geometry [20]

\section{Energy Balance of the system}

Energy balance of the system parts are described by Yıldırım and Solmuş [4, 18, 19]

Glass cover:

$$
0=I \alpha_{g} A_{c}-q_{c, g-a m b}-q_{r, g-s k y}+q_{r, p-g}+q_{c, a-g}
$$

Air channel:

$$
0=q_{c, p-a}-q_{c, a-g}-\dot{m} c_{p}\left(T_{a-o u t}-T_{a-i n}\right)
$$

$\underline{\text { Absorber plate: }}$

$$
0=I \alpha_{p} \tau_{g} A_{c}-q_{c, p-a}-q_{r, p-g}-q_{l o s s, p-a m b}
$$

In general, energy balance of system can be displayed as matrix equation;

$$
[A][T]=[B]
$$

where $[\mathrm{A}]$ is the heat transfer coefficient matrix, [T] is the mean temperature matrix and [B] is the source matrix. This equation can be solved by simple matrix inversion. Calculation of heat transfer equations are discussed in the previous work of Yıldırım and Solmuş [4]. 
Jaurker's [20] correlation of Nusselt number and friction factor are used for roughened absorber plate and Dittus Boelter and Modified Blasius correlations are used for flat (smooth) absorber plate.

$\underline{\text { For flat plate absorber }}$

$$
\begin{aligned}
& N u=0.023 R e^{0.8} P R^{0.4} \\
& f=0.085 R e^{-0.25}
\end{aligned}
$$

$\underline{\text { For transverse wedge shaped rib }}$

$$
\begin{gathered}
N u=0.002062 R e^{0.936} R R H^{0.349} R R P^{3.318} \times \exp \left[-0.868\{\ln (R R P)\}^{2}\right] R R P^{1.108} \times \exp \left[2.486\{\ln (G P P)\}^{2}+\right. \\
\left.1.406\{\ln (G P P)\}^{3}\right] \\
f=0.001227 R e^{-0.199} R R H^{0.585} R R P^{7.19} G P P^{0.645} \times \exp \left[-1.854\{\ln (R R P)\}^{2}\right] \times \exp \left[1.513\{\ln (G P P)\}^{2}+\right. \\
\left.0.8662\{\ln (G P P)\}^{3}\right]
\end{gathered}
$$

Energy efficiency of the collector is evaluated as [2,4];

$$
\eta_{\text {Energy }}=\frac{\dot{m} c_{p}\left(T_{\text {out }}-T_{\text {in }}\right)}{I . A_{c}}
$$

Thermohydraulic efficiency of the collector is evaluated as (Yıldırım and Solmuş [4], Yıldırım and Solmuş [19]);

$$
\eta_{\text {Energy }}=\frac{\dot{m} c_{p}\left(T_{\text {out }}-T_{\text {in }}\right)-P_{\text {fan }}}{I \cdot A_{c}}
$$

Power consumption of fan is evaluated by using the methodology which is detail described in Yıldırım and Solmuş [4]

\section{Solution Procedure}

Considered mathematical model is valid for short collector so that long collector can be assumed to be divided into a number of sections (Ong [2]). Temperature values of first section are initially guessed and heat transfer coefficients are calculated based on guessed values. Then new temperature values are evaluated by using heat transfer coefficients. This iterative process is repeated until all consecutive temperature values less than $0.01{ }^{\circ} \mathrm{C}$. Consecutive section is evaluated as the same procedure. The outlet air temperature of the previous section is set to inlet air temperature of the next one. The ambient temperature $\left(10^{\circ} \mathrm{C}\right)$ is used as initial values. Solar insolation is set to $500 \mathrm{~W} / \mathrm{m}^{2}$. Collector width is set to $1 \mathrm{~m}$, length is set to $2 \mathrm{~m}$ and depth is set to $0.05 \mathrm{~m}$. Tested parameters in this study are represented in Table 1. 
Table 1. Tested parameter values of the study.

\begin{tabular}{|c|c|c|c|c|c|}
\hline \multicolumn{7}{|c|}{ Parameter } \\
\hline RRH (e/D) & 0.018 & 0.024 & 0.030 & 0.036 & \\
\hline RRP (e/p) & 4 & 6 & 8 & 10 & \\
\hline GP/PR (g/p) & 0.3 & 0.4 & 0.5 & 0.6 & 0.7 \\
\hline
\end{tabular}

\section{RESULTS AND DISCUSSION}

A simulation program based on the mathematical model presented in the previous section has been written by MATLAB software. Variations of the thermal and thermohydraulic efficiency with respect to Reynolds number are investigated for different roughness parameters.

Figure 2 and Figure 3 show the effect of the relative roughness height (RRH) on the thermal efficiency and the thermauhydrolic efficiency, respectively. As the Reynolds number increases, thermal efficiency increases with the increasing RRH value in Figure 2. Moreover, thermauhydrolic efficiency is positively affected by increasing Re number until a certain point as can be seen in Figure 3 . Increasing Reynolds number increases the pressure drops so it lead to slightly reduce the thermohydraulic efficiency.

Increasing RRH enhance the turbulence therefore thermal efficiency increases. On the other hand high turbulence intensity cause to pressure drop, thus increasing RRH slightly reduce the thermohydraulic efficiency.

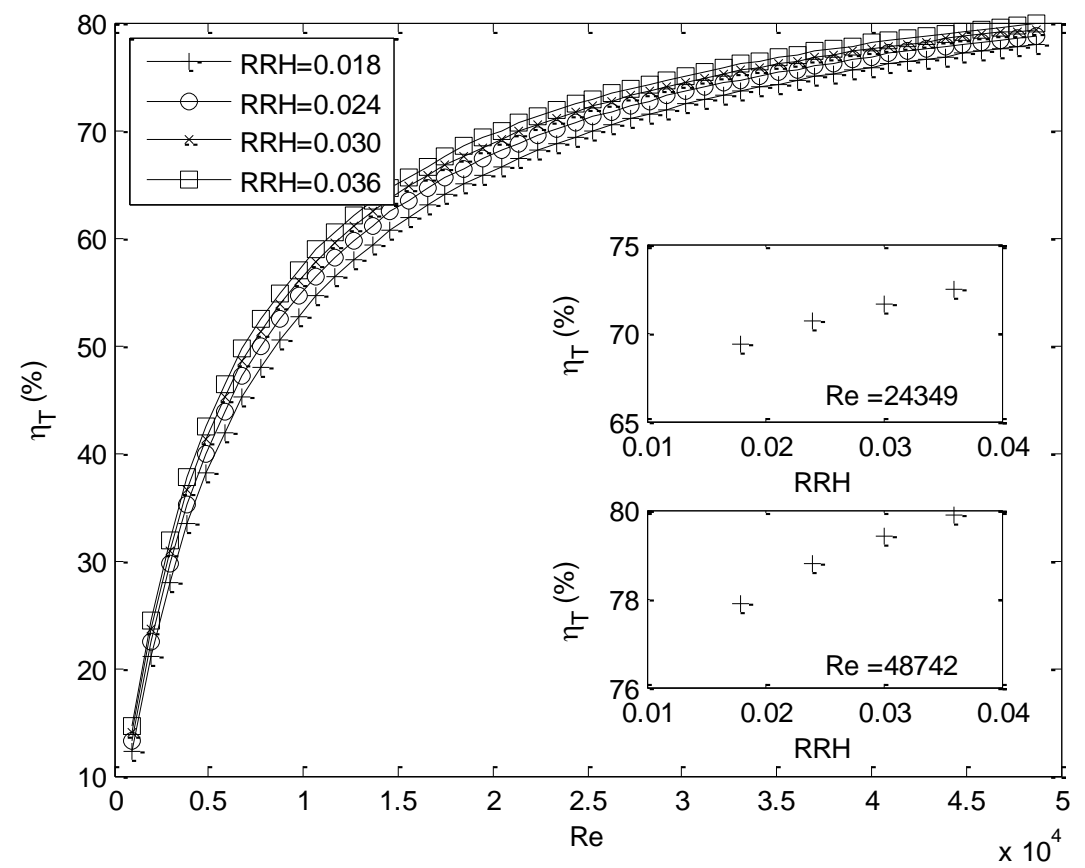

Figure 2. Effect of the Relative Roughness Height (RRH) on the thermal efficiency.

Figure 4 and Figure 5 exhibit the effect of the relative roughness pitch (RRP) on the thermal efficiency and the thermohydraulic efficiency, respectively. Thermal efficiency increases by increasing RRP (Figure 4) while the thermohydraulic efficiency increases until a certain point and then it barely fall down.

In addition to that optimum RRP values are found as 6 for thermal efficiency for all Reynolds number range (Figure 4). On the other hand optimum RRP values are found as 6 for thermohydraulic efficiency for low Reynolds number and 4 for high Reynolds number (Figure 5). 
Journal of Thermal Engineering, Research Article, Vol. 4, No. 1, pp. 1702-1712, January, 2018

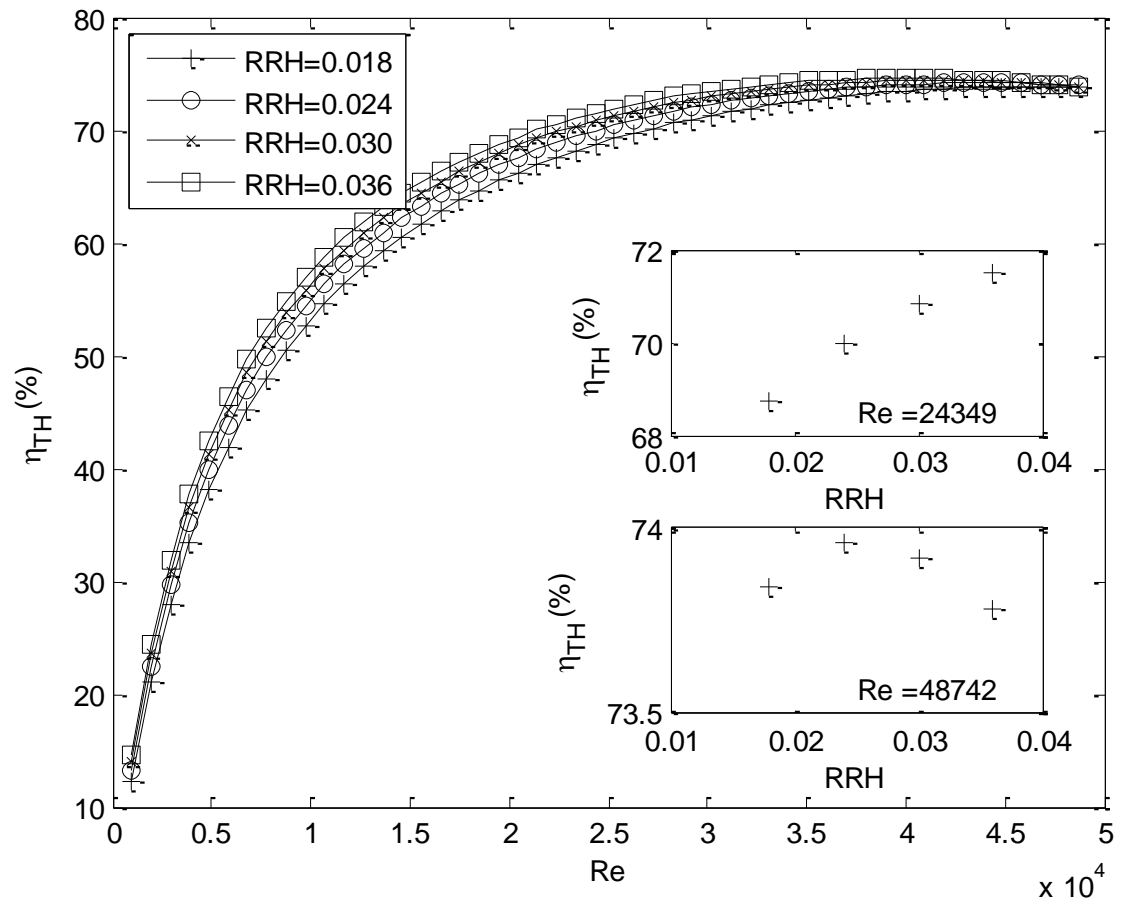

Figure 3. Effect of the Relative Roughness Height (RRH) on the thermauhydrolic efficiency.

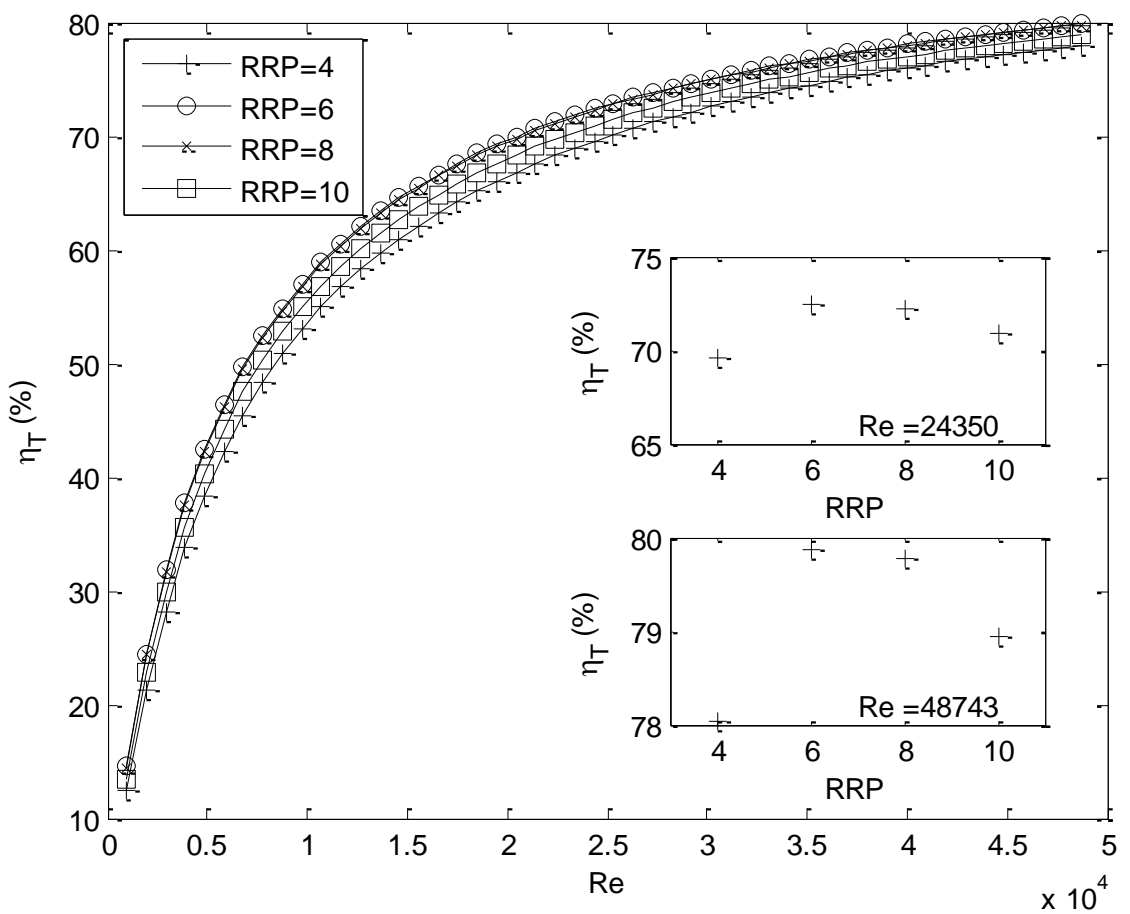

Figure 4. Effect of the Relative Roughness Pitch (RRP) on the thermal efficiency. 


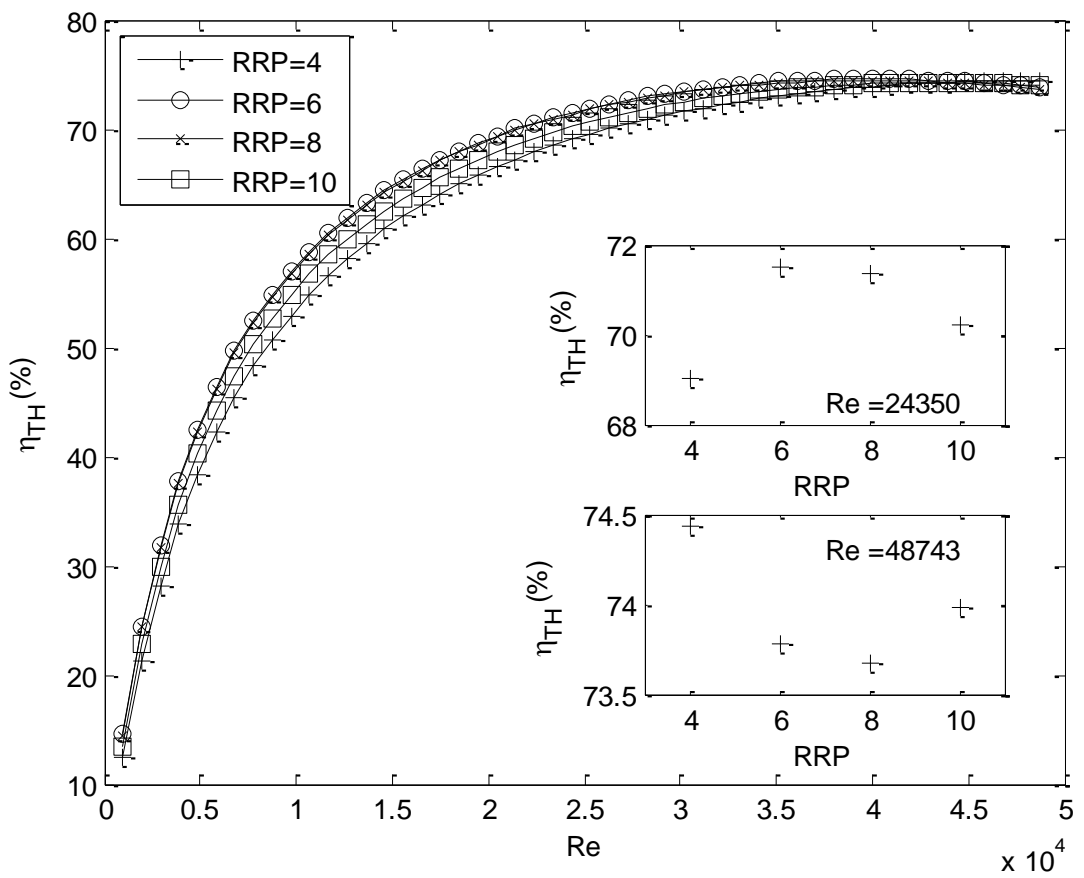

Figure 5: Effect of the Relative Roughness Pitch (RRP) on the thermohydraulic efficiency.

The other important parameter is the ratio of Groove position to pitch ratio (GP/PR). As can be seen from Figure 6 and Figure 7, the same situation which is occurred in Figures 4 and 5, is observed for thermal and thermohydraulic efficiencies. Namely, positive effect of the increasing Re number continues to be observed. The optimum GP/PR value is calculated as 0.4 for thermal and thermohydraulic efficiencies.

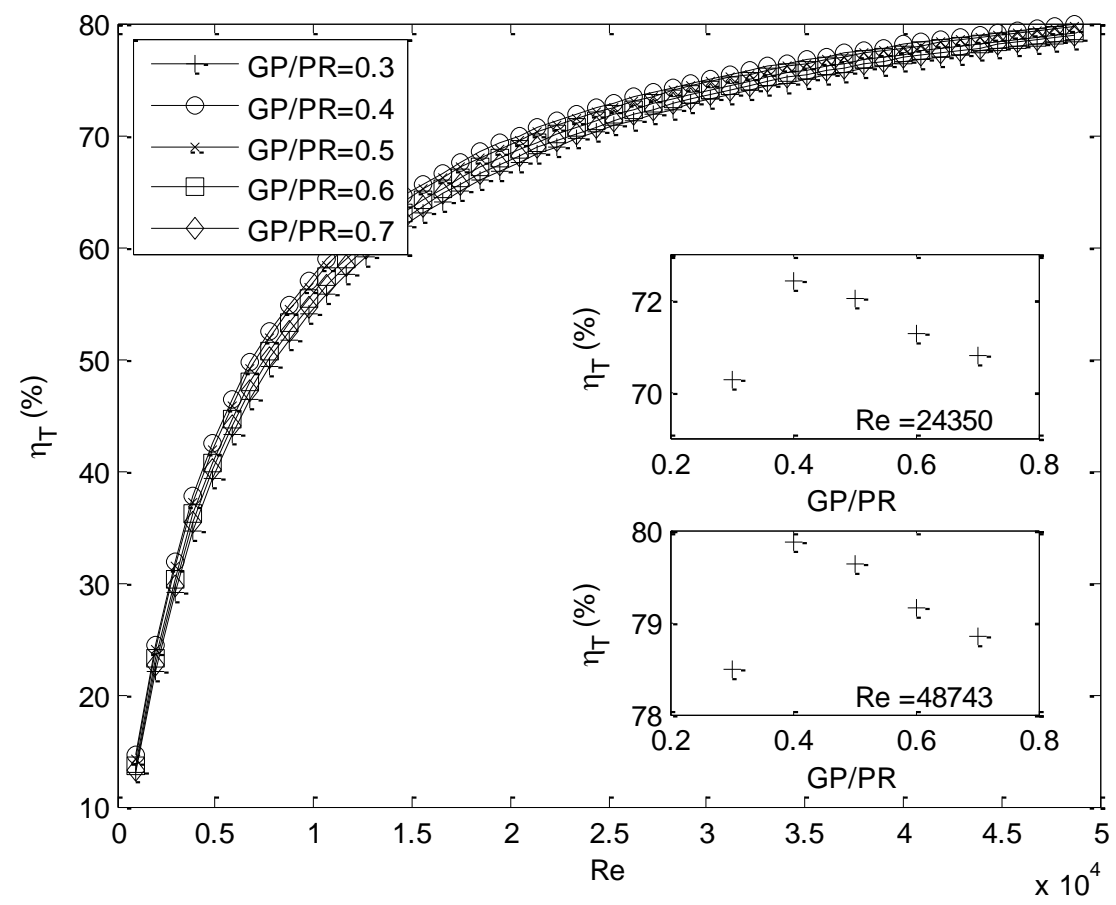

Figure 6: Effect of the ratio of Groove Position to Pitch Ratio (GP/PR) on the thermal efficiency. 


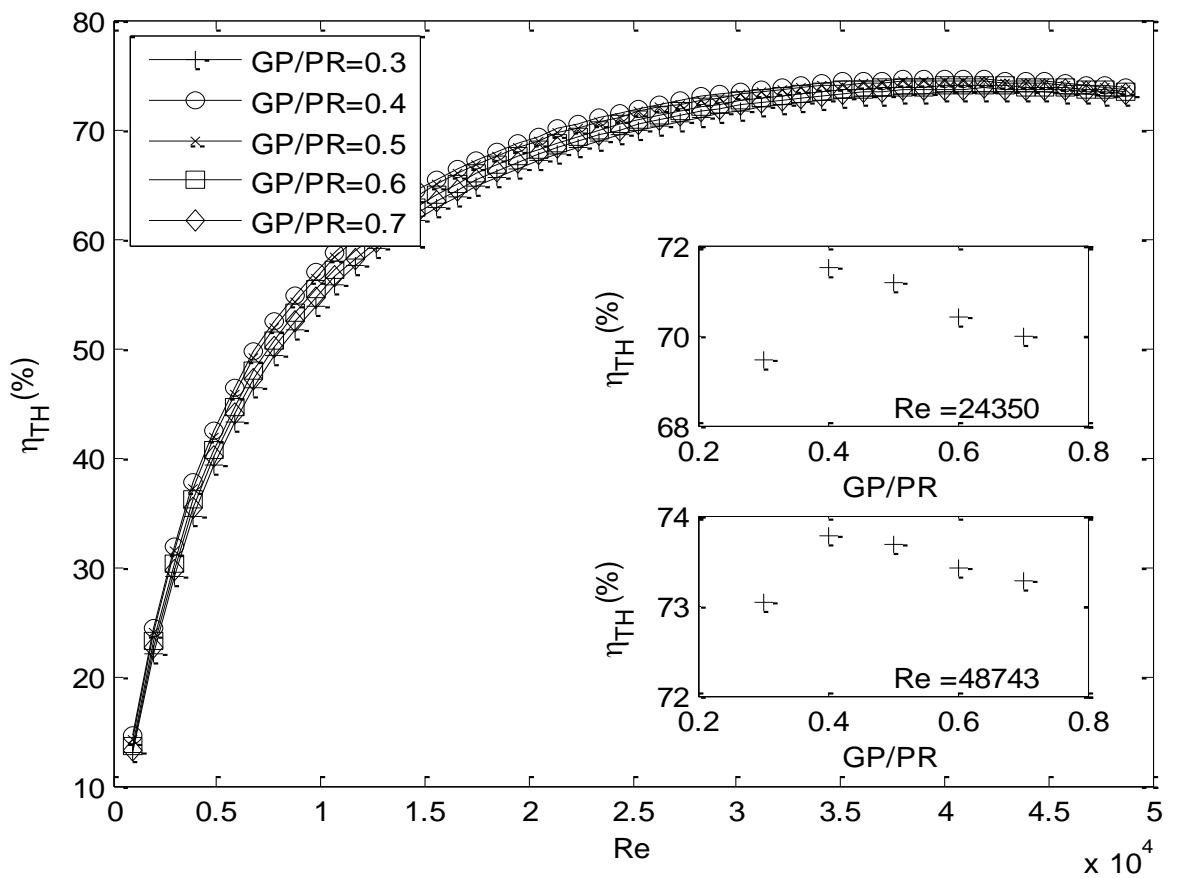

Figure 7. Effect of the ratio of Groove Position to Pitch Ratio (GP/PR) on the thermohydraulic efficiency.

The smooth absorber and roughened with rib \& grooved absorber are compared in terms of thermal efficiency in Figure 8 while they are compared in terms of thermauhydrolic efficiency in Figure 9. By using rib \& grooved absorber, thermal and thermauhydrolic efficiencies is increased from $\% 60$ to \%80. It is observed that, if Reynolds number is further increased, pressure drop become to be important (Figure 9).

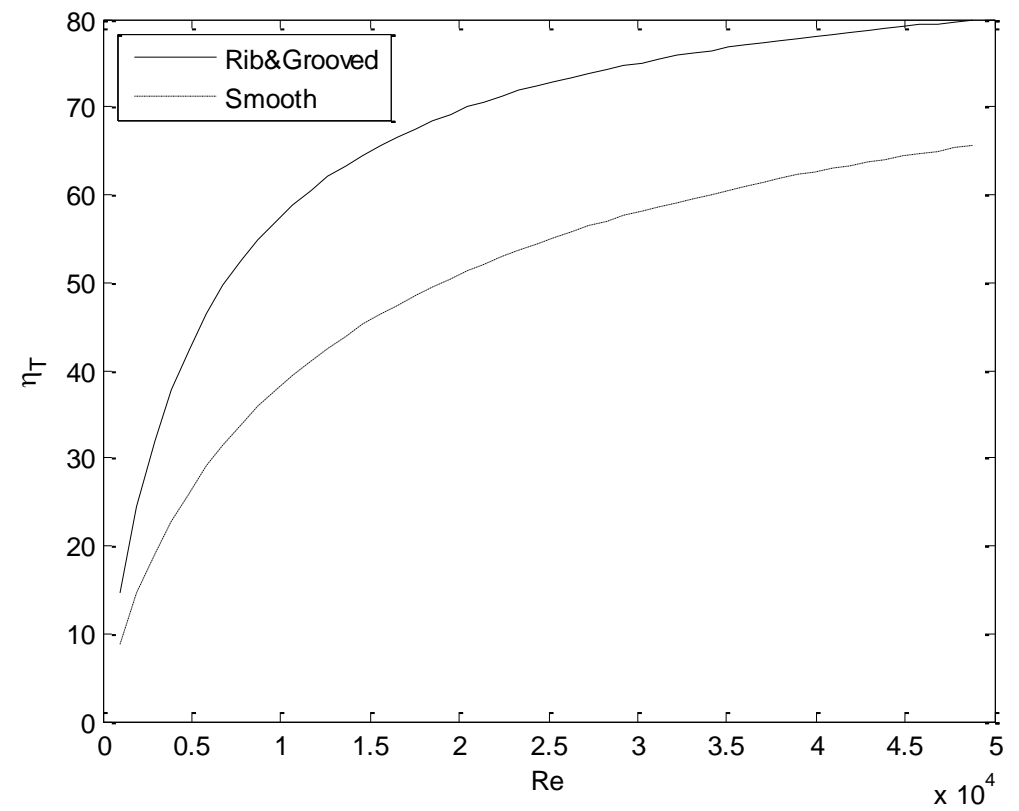

Figure 8. Comparison of thermal efficiency of smooth absorber and roughened with rib \& grooved absorber. 


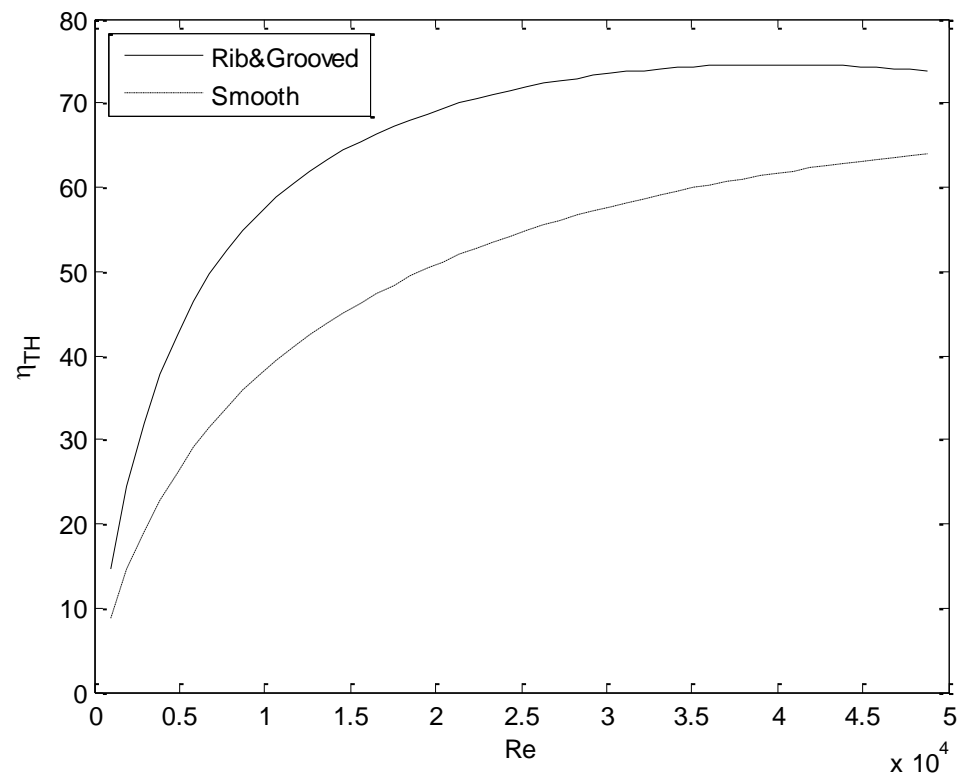

Figure 9. Comparison of thermauhydrolic efficiency of smooth absorber and roughened with rib \& grooved absorber.

\section{CONCLUSION}

In this study, thermal and thermohydraulic efficiencies of a solar air collector having rib and groove shaped roughness elements have been investigated. Main findings can be summarized as follows:

- Thermal efficiency increases by increasing Reynolds number for all roughness parameters.

- Thermohydraulic efficiency increases by increasing Reynolds number up to its maximum value and then slightly decreases due to increasing friction of the air flow.

- $\quad$ Relative roughness height (RRH) increases the thermal and thermohydraulic efficiencies.

- $\quad$ Relative roughness pitch (RRP) increases the thermal and thermohydraulic efficiencies up to a certain point and then decreases.

- Groove Position to Pitch Ratio (GP/PR) increases the thermal and thermohydraulic efficiencies up to a certain point and then decreases.

- $\quad$ Artificially roughened absorber plate with rib \& grooved absorber has superiority on smooth absorber plate.

\section{NOMENCLATURE}

f : Friction factor

I : Solar radiation $(\mathrm{W} / \mathrm{m} 2)$

$\mathrm{Nu} \quad$ : Nusselt number

Re : Reynolds number

RRH : Relative roughness height (e/D)

RRP : Relative roughness pitch (p/e)

GP/PR : Groove position to pitch ratio (g/p)

W : Width of duct

$\mathrm{H} \quad$ : Height of duct

D : Equivalent diameter of duct $\left(D=4^{*} \mathrm{~W}^{*} \mathrm{H} /\left(2^{*}(\mathrm{~W}+\mathrm{H})\right)\right.$

$\eta \quad$ : Efficiency

T : Thermal 
Journal of Thermal Engineering, Research Article, Vol. 4, No. 1, pp. 1702-1712, January, 2018

$\begin{array}{ll}\text { TH } & \text { : Thermohydraulic } \\ \text { a-in } & \text { : Air at the inlet } \\ \text { a-out } & \text { : Air at the outlet } \\ \text { c } & \text { : Collector } \\ \text { c,a-g } & \text { : Convection from air to glazing } \\ \text { c,g-amb } & \text { : Convection from glazing to ambient } \\ \text { c,p-a } & \text { : Convection from plate to air } \\ \text { r,g-sky } & \text { : Radiation from glazing to sky } \\ \text { r,p-g } & \text { : Radiation from plate to glass } \\ \text { loss,p-amb } & \text { : Loss from plate to ambient }\end{array}$

\section{REFERENCES}

[1]Oztop, H. F., Bayrak, F., \& Hepbasli, A. (2013). Energetic and exergetic aspects of solar air heating (solar collector) systems. Renewable and Sustainable Energy Reviews, 21, 59-83.

[2]Ong, K. S. (1995). Thermal performance of solar air heaters: mathematical model and solution procedure. Solar energy, 55(2), 93109.

[3]Ong, K. S. (1995). Thermal performance of solar air heaters—Experimental correlation. Solar Energy, 55(3), 209-220.

[4]Yildirim, C., \& Solmuş, İ. (2014). Çift Geçişli Hava Akişkanli Güneş Toplaci Kanal Yüksekliğinin Termohidrolik Verime Etkisinin İncelenmesi. Isi Bilimi Ve Teknigi Dergisi/Journal Of Thermal Science \& Technology, 34(1).

[5]Yadav, A. S., \& Bhagoria, J. L. (2014). A numerical investigation of square sectioned transverse rib roughened solar air heater. International Journal of Thermal Sciences, 79, 111-131.

[6]Acir, A., \& Ata, İ. (2016). A study of heat transfer enhancement in a new solar air heater having circular type turbulators. Journal of the Energy Institute, 89(4), 606-616.

[7]Rajaseenivasan, T., Srinivasan, S., \& Srithar, K. (2015). Comprehensive study on solar air heater with circular and V-type turbulators attached on absorber plate. Energy, 88, 863-873.

[8]Yang, M., Yang, X., Li, X., Wang, Z., \& Wang, P. (2014). Design and optimization of a solar air heater with offset strip fin absorber plate. Applied Energy, 113, 1349-1362.

[9]Saxena, A., Srivastava, G., \& Tirth, V. (2015). Design and thermal performance evaluation of a novel solar air heater. Renewable Energy, 77, 501-511.

[10]Alam, T., Saini, R. P., \& Saini, J. S. (2014). Effect of circularity of perforation holes in V-shaped blockages on heat transfer and friction characteristics of rectangular solar air heater duct. Energy Conversion and Management, 86, 952-963.

[11]Yadav, S., \& Kaushal, M. (2014). Exergetic performance evaluation of solar air heater having arc shape oriented protrusions as roughness element. Solar Energy, 105, 181-189.

[12]Alam, T., Saini, R. P., \& Saini, J. S. (2014). Experimental investigation on heat transfer enhancement due to V-shaped perforated blocks in a rectangular duct of solar air heater. Energy Conversion and Management, 81, 374-383.

[13]Nowzari, R., Mirzaei, N., \& Aldabbagh, L. B. Y. (2015). Finding the best configuration for a solar air heater by design and analysis of experiment. Energy Conversion and Management, 100, 131-137.

[14]Jin, D., Zhang, M., Wang, P., \& Xu, S. (2015). Numerical investigation of heat transfer and fluid flow in a solar air heater duct with multi V-shaped ribs on the absorber plate. Energy, 89, 178-190.

[15]Verma, P., \& Varshney, L. (2015). Parametric investigation on thermo-hydraulic performance of wire screen matrix packed solar air heater. Sustainable Energy Technologies and Assessments, 10, 40-52.

[16]Deo, N. S., Chander, S., \& Saini, J. S. (2016). Performance analysis of solar air heater duct roughened with multigap V-down ribs combined with staggered ribs. Renewable Energy, 91, 484-500.

[17] Singh, S., Chander, S., \& Saini, J. S. (2015). Thermo-hydraulic performance due to relative roughness pitch in V-down rib with gap in solar air heater duct_-Comparison with similar rib roughness geometries. Renewable and Sustainable Energy Reviews, 43, 11591166 .

[18]Yıldırım C., Solmuş İ. (2013). First and second law analysis of various types of solar air heaters, 8th Conference on Sustainable Development of Energy, Water and Environment Systems, Dubrovnik-Croatia, September 22-27. 
[19]Yıldırım C., Solmuş İ. (2015). Energy and Exergy Analysis of a Solar Air Collector Having a Roughened Absorber with Circular Protrusions, International Conference on Environment and Renewable Energy, Vienna, Austria, May 20-21.

[20]Jaurker, A. R., Saini, J. S., \& Gandhi, B. K. (2006). Heat transfer and friction characteristics of rectangular solar air heater duct using rib-grooved artificial roughness. Solar Energy, 80(8), 895-907. 